\title{
Sex Differences in Frailty of Geriatric Outpatients With Type 2 Diabetes Mellitus: A Multicentre Cross- sectional Study
}

Huan Nguyen ( $\nabla$ huannguyen@ump.edu.vn )

Ho Chi Minh City Medicine and Pharmacy University

An Nguyen

Ho Chi Minh City Medicine and Pharmacy University

Phuong Le

Ho Chi Minh City Medicine and Pharmacy University

\section{Research Article}

Keywords: frailty, diabetes mellitus, prevalence, older outpatients

Posted Date: March 7th, 2022

DOI: https://doi.org/10.21203/rs.3.rs-1404489/v1

License: (c) (i) This work is licensed under a Creative Commons Attribution 4.0 International License.

Read Full License 


\section{Abstract}

Purpose Frailty and type 2 diabetes mellitus (T2DM) can occur concurrently and are increasingly prevalent in older populations. There is a marked variability in frailty progression between men and women. This study aimed to investigate sex differences in the prevalence and factors associated with frailty in older outpatients with T2DM.

Methods This multicentre cross-sectional study included 638 outpatients (aged $\geq 60$ years; mean age $71.9 \pm 7.2$ years; male 55.5\%) and was conducted from January 2019 to July 2020. Frailty was assessed using the Fried frailty phenotype. Factors associated with frailty were assessed using a logistic regression analysis.

Results The overall frailty prevalence was $28.2 \%$ (men, $26.8 \%$; women, $29.9 \% ; P=0.388$ ). In the adjusted model, the factors associated with greater odds of being frail were older age (odds ratio [OR], 1.08; $95 \%$ confidence interval [CI], 1.05-1.11; $P<0.001)$ and body mass index (BMI) less than $20 \mathrm{~kg} / \mathrm{m}^{2}(\mathrm{OR}, 1.96$; $95 \% \mathrm{Cl}, 1.16-3.32 ; P=0.012)$. Higher education (OR, 0.64; $95 \% \mathrm{Cl}, 0.42-0.98 ; P=0.041)$ and productive work $(\mathrm{OR}, 0.11 ; 95 \% \mathrm{Cl}, 0.03-0.36 ; P<0.001)$ were protective factors against frailty. Frailty was associated with all four factors in women, but only with older age and productive work in men.

Conclusion Women were more likely to be frail compared with men with T2DM, although the difference was not significant. While older age and BMI less than $20 \mathrm{~kg} / \mathrm{m}^{2}$ can increase the odds of frailty, and higher education and productive work can decrease the odds of frailty in women, only age and productive work were associated with frailty in men with T2DM.

\section{Introduction}

Frailty is an important geriatric syndrome characterised by increased vulnerability and decreased ability of older adults to regain homeostasis following stressor events ${ }^{1}$. The prevalence of frailty increases with age, and the presence and severity of this clinical state can influence the manifestation and clinical outcomes of multiple comorbidities, including endocrine and cardiovascular diseases ${ }^{2,3}$. Fortunately, frailty, a risk factor for the development of major adverse cardiovascular events, is preventable and reversible, with early diagnosis and appropriate intervention ${ }^{4,5}$.

Type 2 diabetes mellitus (T2DM) is a major global health and economic burden due to an ageing population ${ }^{6}$. Management of T2DM in older adults is difficult owing to the coexistence of geriatric syndromes, such as polypharmacy, polymorbidity, falls, delirium, and frailty ${ }^{7}$. Frailty is not only an independent predictor of incident T2DM in older adults ${ }^{8}$, but is also associated with mortality, complications, and lower quality of life in people with diabetes ${ }^{2}$. The identification and assessment of frailty is increasingly recognised in recent clinical guidelines for diabetes to determine targets and therapeutic approaches for older patients with $T 2 \mathrm{DM}^{9,10}$. 
Accumulating evidence has shown that there is a male-female health-survival paradox in the older population. Although women have a longer life expectancy than men ${ }^{11}$, systematic reviews of community-dwelling populations have found greater levels of disability, more comorbidities, and a higher prevalence of frailty in older women than in older men ${ }^{12,13}$. The discrepancy between health and survival may suggest that women tolerate frailty better than men. It may also be related to the differences in social, behavioural, and biological factors between the two groups ${ }^{14,15}$.

Vietnam, a lower middle-income country, entered a growth phase in their ageing population in 2011. In 2019 , people aged $\geq 60$ years accounted for $13.2 \%$ (men, $6.1 \%$; women, $7.2 \%$ ) of the total Vietnamese population ${ }^{16}$. The country has also undergone an epidemiological transition, with health alterations from infectious diseases to non-communicable diseases ${ }^{17}$. In Vietnam, $6 \%$ of the total population had diabetes ${ }^{18}$, and among older individuals, the diabetes rate was approximately $29 \%{ }^{19}$. However, little clinical information is available to understand whether the characteristics of frailty in older adults with T2DM differ between the sexes. Therefore, the aim of this study was to investigate sex differences in the prevalence and factors associated with frailty in older outpatients with T2DM.

\section{Material And Methods}

\section{Study design and participants}

This cross-sectional study was conducted in outpatients aged $\geq 60$ years with T2DM at three geriatric clinics from January 2019 to July 2020. Participants met the inclusion criteria if they were diagnosed with T2DM for one year or more before enrolment based on a fasting plasma glucose level of $\geq 7.0$ $\mathrm{mmol} / \mathrm{L}$ after no caloric intake for at least 8 hours and/or haemoglobin A1c (HbA1c) level of $\geq 6.5 \%$. To ensure consistent management, trained geriatricians treated all patients for T2DM with any medication and with individualised $\mathrm{HbA} 1 \mathrm{c}$ targets based on the recent guidelines of the European Society of Cardiology and European Association for the Study of Diabetes ${ }^{10}$. Exclusion criteria were hospital admission, active malignancy, serious mental condition, or heart failure categorised as New York Heart Association class III-IV. All participants provided written informed consent and underwent a comprehensive geriatric assessment, including demographic characteristics, Fried frailty phenotype, and comorbidities.

\section{Sample size calculation}

The sample size was calculated for the first aim of this study using a single population proportion formula: $n=Z^{2}{ }_{1-a / 2}{ }^{*}\left[p^{*}(1-p) / d^{2}\right]$, where $n=$ the required sample size, $Z_{1-\alpha / 2}=1.96$ (with $a=0.05$, and $95 \%$ confidence interval), $p=$ prevalence of frailty in older outpatients with T2DM in Vietnam, and $d=$ precision (assumed as 0.04 ). Because the prevalence is unknown, we set $p$ as 0.5 to obtain the maximum possible value of $p^{\star}(1-p)$ as 0.25 . This study required a minimum of 600 participants.

\section{Variables and definitions}


Geriatricians managing the patients were responsible for collecting demographic data, clinical characteristics, and measuring body weight and height. Self-reported information was obtained on age, sex, marital status, level of education, living status (alone or with anyone), and productive work. The patients' educational level was classified as lower education (no school, elementary, and junior high school) or higher education (senior high school, university, and above). Productive work was defined as participants having any form of paid or unpaid job. Comorbidities were obtained from interviews and electronic medical records. Polypharmacy and multimorbidity data were collected based on the prescriptions of the patients. Polypharmacy was defined as five or more medications. Multimorbidity was defined as the presence of two or more chronic diseases.

Body mass index (BMI) was calculated as the quotient of body weight $(\mathrm{kg})$ and height $\left(\mathrm{m}^{2}\right)$. Body weight and height were measured following a standardised protocol using identical equipment at all study sites. Because of the differences in body mass index classifications between the World Health Organization and Asia-Pacific guidelines, the BMI of our patients was categorised into five groups $(<20,20-24.9,25-$ $29.9,30-34.9$, and $\geq 35 \mathrm{~kg} / \mathrm{m}^{2}$ ) according to a previous study investigating the relationship between frailty and $\mathrm{BMI}$ in older people $\mathrm{e}^{20}$.

\section{Assessment of frailty}

Patients were physically examined and placed into one of three categories using the Fried frailty phenotype: frail ( $\geq 3$ criteria present), pre-frail ( $1-2$ criteria present), or non-frail ( 0 criteria present) ${ }^{21}$. A Vietnamese version of Fried criteria was carefully explained to each patient, and caregivers were asked to ensure that the reporting context was correct. The five components are as follows.

1. Unintentional weight loss of $\geq 4.5 \mathrm{~kg}$ or $\geq 5 \%$ body weight in the past year.

2. Weakness: Grip strength of the dominant hand was measured once in the sitting position using a Jamar 5030-J1 hydraulic hand dynamometer (JLW Instruments, Chicago, IL 60607, United States) with relaxed shoulders and encouragement. Weakness was defined as the lowest quintile of grip strength, stratified according to sex and body mass index (BMI). The BMI cut-off points were $\leq 29.0$, $\leq 30.0$, and $\leq 32.0 \mathrm{~kg}$ for $\mathrm{BMI} \leq 24.0,24.1-28.0$, and $>28.0$, respectively, in men and $\leq 17.0, \leq 17.3$, $\leq 18.0$, and $\leq 21.0 \mathrm{~kg}$ for $\mathrm{BMI} \leq 23.0 ; 23.1-26.0$; $\leq 26.1-29.0$, and $>29.0$, respectively, in women.

3. Exhaustion: Two questions from the Centre for Epidemiologic Studies Depression Scale were used: 'I felt that everything I did was an effort last week' and 'I could not get going last week' ${ }^{21}$. Participants answering 'frequently' or 'always' to at least one of these two questions were categorised as having met the criterion for exhaustion.

4. Slowness: The walking time of participants over a $4.57 \mathrm{~m}$ distance was adjusted for gender and height. The cut-off points for slow walking speed were established as height $\leq 173 \mathrm{~cm}$ and time $\geq 7$ $\mathrm{s}$ (equivalent to $0.65 \mathrm{~m} / \mathrm{s}$ ) or height $>1.73 \mathrm{~cm}$ and time $\geq 6 \mathrm{~s}$ (equivalent to $0.76 \mathrm{~m} / \mathrm{s}$ ) for men, and height $\leq 1.59 \mathrm{~cm}$ and time $\geq 7 \mathrm{~s}(0.65 \mathrm{~m} / \mathrm{s})$ or height $>1.59 \mathrm{~cm}$ and time $\geq 6 \mathrm{~s}(0.76 \mathrm{~m} / \mathrm{s})$ for women. 
5. Low physical activity: We used the short version of the Minnesota Leisure Time Activity questionnaire, which included questions on 18 activities: walking, chores, mowing the lawn, raking, gardening, hiking, jogging, biking, exercise cycling, dancing, aerobics, bowling, golf, singles tennis,

doubles tennis, racquetball, callisthenics, and swimming ${ }^{21}$. The total weekly kilocalories of physical activity expenditure were calculated using a standardised algorithm. Low activity levels were defined as $<383 \mathrm{kcal}$ in men and $<270 \mathrm{kcal}$ in women.

\section{Statistical analysis}

All collected data were analysed using the IBM SPSS Statistics for Windows, version 25 (IBM Corp., Armonk, NY, USA). Categorical variables were described as frequencies and percentages (\%). Continuous variables were described using means and standard deviations. Chi-square test or Fisher's exact test was used to compare categorical variables. Student's t-test or one-way ANOVA was used to determine the statistical significance of the difference between two or more study group means. To determine factors associated with frailty, the non-frail and pre-frail groups were pooled together in a non-frail group. Univariate logistic regression analysis was performed to identify potential factors associated with frailty. Variables with $P$ values $<0.2$ in the univariate analysis, were selected for multivariate logistic regression. All variables were examined for their interaction and multicollinearity. All tests were two-sided, and the significance level was set at $P<0.05$.

\section{Results}

\section{Prevalence of frailty in older outpatients with T2DM}

Of the 2215 patients admitted to our geriatric clinics during the study period, 1577 were excluded because they did not have diabetes (1544 patients), required hospital admission (17 patients), had serious mental conditions (6 patients), or had missing responses (10 patients). The 638 older patients with T2DM enrolled in this study had a mean age of $71.9 \pm 7.2$ (range, 60-92) years and male predominance (55.5\%). The overall prevalence of non-frail, pre-frail, and frail categories was $17.9 \%(n=114), 53.9 \%(n=$ $344)$, and $28.2 \%(n=180)$, respectively.

\section{Differences in main characteristics between men and women}

Table 1 summarises the characteristics of the patients according to sex. The men and women did not differ in terms of living status, productive work, polypharmacy, multimorbidity, and some medical disorders (i.e. hypertension, heart failure, stroke, and chronic pulmonary diseases). However, there were significant differences in age, marital status, level of education, BMI group, coronary artery disease, osteoarthritis, and chronic kidney disease between the two groups. The women's group was significantly older than the men's group (72.8 \pm 7.2 vs $71.1 \pm 7.1, P=0.003)$, and there were more women than men aged 75 years and over $(46.1 \%$ vs. $31.1 \%, P<0.001)$. Importantly, the women's group had a significantly 
lower rate of higher education than the men's group $(37.7 \%$ vs. $76.3 \%, P<0.001)$. The two most common conditions in both groups were hypertension and osteoarthritis, followed by chronic kidney disease in the men's group and coronary heart disease in the women's group. 
Table 1

Characteristics of the participants according to sex

\begin{tabular}{|c|c|c|c|c|}
\hline Characteristics & $\begin{array}{l}\text { All } \\
(n=638)\end{array}$ & $\begin{array}{l}\text { Men } \\
(n=354)\end{array}$ & $\begin{array}{l}\text { Women } \\
(n=284)\end{array}$ & $P$-value ${ }^{\mathrm{a}}$ \\
\hline Age, years & $71.9 \pm 7.2$ & $71.1 \pm 7.1$ & $72.8 \pm 7.2$ & 0.003 \\
\hline Age $\geq 75$ years, $n(\%)$ & $241(37.8)$ & $110(31.1)$ & $131(46.1)$ & $<0.001$ \\
\hline Marital status, n (\%) & & & & $<0.001$ \\
\hline Single & $7(1.1)$ & $0(0)$ & $7(2.5)$ & \\
\hline Married & $477(74.8)$ & $328(92.7)$ & $149(52.5)$ & \\
\hline Divorced/Widowed & $154(24.1)$ & $26(7.3)$ & $128(45.0)$ & \\
\hline Higher education, n (\%) & $377(59.1)$ & $270(76.3)$ & 107 (37.7) & $<0.001$ \\
\hline Living alone, n (\%) & $72(11.3)$ & $34(9.6)$ & $38(13.4)$ & 0.170 \\
\hline Productive work, n (\%) & $74(11.6)$ & $43(12.1)$ & $31(10.9)$ & 0.720 \\
\hline $\mathrm{BMI}, \mathrm{kg} / \mathrm{m}^{2}$ & $22.9 \pm 3.1$ & $23.0 \pm 2.9$ & $22.8 \pm 3.4$ & 0.369 \\
\hline BMI groups, n (\%) & & & & 0.001 \\
\hline$<20$ & $101(15.8)$ & $51(14.4)$ & $50(17.6)$ & \\
\hline $20-24.9$ & $379(59.4)$ & $207(58.5)$ & $172(60.6)$ & \\
\hline $25-29.9$ & $147(23.1)$ & $95(26.8)$ & $52(18.3)$ & \\
\hline $30-34.9$ & $11(1.7)$ & $1(0.3)$ & $10(3.5)$ & \\
\hline Polypharmacy, n (\%) & $367(57.5)$ & $212(59.9)$ & $155(54.6)$ & 0.205 \\
\hline Multimorbidity, n (\%) & $591(92.6)$ & 327 (92.4) & $264(93.0)$ & 0.898 \\
\hline \multicolumn{5}{|l|}{ Medical disorders, n (\%) } \\
\hline Hypertension & $566(88.7)$ & $320(90.4)$ & $246(86.6)$ & 0.170 \\
\hline Coronary artery disease & $172(27.0)$ & $65(18.4)$ & 107 (37.7) & $<0.001$ \\
\hline Heart failure & $8(1.3)$ & $4(1.1)$ & $4(1.4)$ & 0.753 \\
\hline
\end{tabular}

Categorical variables are described as frequencies ( $n$ ) and percentages (\%). Continuous variables are described using means and standard deviations. Comparisons were conducted using the chi-square test or Fisher's exact test for categorical variables and Student's t-test for continuous variables.

aMen's group vs. women's group

eGFR estimated glomerular filtration rate, $B M /$ body mass index 


\begin{tabular}{|c|c|c|c|c|}
\hline Characteristics & $\begin{array}{l}\text { All } \\
(n=638)\end{array}$ & $\begin{array}{l}\text { Men } \\
(n=354)\end{array}$ & $\begin{array}{l}\text { Women } \\
(n=284)\end{array}$ & $P$-value ${ }^{a}$ \\
\hline Stroke & $21(3.3)$ & $14(4.0)$ & $7(2.5)$ & 0.409 \\
\hline Osteoarthritis & $355(55.6)$ & $212(59.9)$ & $143(50.4)$ & 0.020 \\
\hline Chronic pulmonary diseases & $18(2.8)$ & $6(1.7)$ & $12(4.2)$ & 0.093 \\
\hline $\mathrm{eGFR}<60 \mathrm{~mL} / \mathrm{min} / 1.73 \mathrm{~m}^{2}$ & $224(35.1)$ & $148(41.8)$ & $76(26.8)$ & $<0.001$ \\
\hline \multicolumn{5}{|c|}{$\begin{array}{l}\text { Categorical variables are described as frequencies }(\mathrm{n}) \text { and percentages }(\%) \text {. Continuous variables are } \\
\text { described using means and standard deviations. Comparisons were conducted using the chi-square } \\
\text { test or Fisher's exact test for categorical variables and Student's t-test for continuous variables. }\end{array}$} \\
\hline \multicolumn{5}{|l|}{ 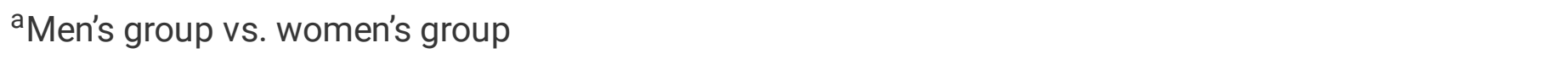 } \\
\hline eGFR estimated glomerular fil & ate, $B M /$ body & ss index & & \\
\hline
\end{tabular}

\section{Differences in main characteristics between the Fried frailty phenotype groups}

To further understand the characteristics of frailty in older outpatients with T2DM, we compared the participants according to the frailty phenotype (Table 2 ). There was a trend for increasing age between the three groups with the mean age of non-frail, pre-frail, and frail individuals being $69.7 \pm 6.8,70.8 \pm 6.5$, and $75.2 \pm 7.6$ years, respectively $(P<0.001)$. Furthermore, there were significant differences between the three frailty phenotype groups in terms of sex, $\mathrm{BMI}$, and productive work. Women $(47.2 \%)$ and $\mathrm{BMI}<20$ $\mathrm{kg} / \mathrm{m}^{2}(22.2 \%)$ were the most prevalent, whereas those with any form of job $(1.7 \%)$ were the lowest in the frail group. Although there were no statistically significant differences among the three groups in marital status, level of education, living alone, polypharmacy, multimorbidity, and medical disorders, the rate of divorced/widowed was higher in the frail group than in the pre-frail and non-frail groups $(31.1 \%, 23.0 \%$, and $16.7 \%$, respectively), and there were fewer highly educated older adults in the frail group than in the pre-frail and non-frail groups $(52.8 \%, 60.2 \%$, and $65.8 \%$, respectively). Hypertension, osteoarthritis, and chronic kidney disease were the three most prevalent medical disorders, and were more frequently reported in the frail group. 
Table 2

Characteristics of the participants according to the Fried frailty phenotype

\begin{tabular}{|c|c|c|c|c|c|}
\hline Characteristics & $\begin{array}{l}\text { All } \\
(n=638)\end{array}$ & $\begin{array}{l}\text { Nonfrail } \\
(n=114)\end{array}$ & $\begin{array}{l}\text { Prefrail } \\
(n=344)\end{array}$ & $\begin{array}{l}\text { Frail } \\
(n=180)\end{array}$ & $P$-value \\
\hline Age, years & $71.9 \pm 7.2$ & $69.7 \pm 6.8$ & $70.8 \pm 6.5$ & $75.2 \pm 7.6$ & $<0.001$ \\
\hline Age $\geq 75$ years, $n(\%)$ & $241(37.8)$ & $27(23.7)$ & $112(32.6)$ & $102(56.7)$ & $<0.001$ \\
\hline Men, n (\%) & $354(55.5)$ & $76(66.7)$ & $183(53.2)$ & $95(52.8)$ & 0.028 \\
\hline Marital status, n (\%) & & & & & 0.056 \\
\hline Single & $7(1.1)$ & $2(1.8)$ & $4(1.2)$ & $1(0.6)$ & \\
\hline Married & $477(74.8)$ & $93(81.5)$ & $261(75.8)$ & $123(68.3)$ & \\
\hline Divorced/Widowed & $154(24.1)$ & $19(16.7)$ & $79(23.0)$ & $56(31.1)$ & \\
\hline Higher education, n (\%) & $377(59.1)$ & $75(65.8)$ & $207(60.2)$ & $95(52.8)$ & 0.072 \\
\hline Living alone, n (\%) & $72(11.3)$ & $18(15.8)$ & $36(10.5)$ & $18(10.0)$ & 0.269 \\
\hline Productive work, n (\%) & $74(11.6)$ & $32(28.1)$ & $39(11.3)$ & $3(1.7)$ & $<0.001$ \\
\hline $\mathrm{BMI}, \mathrm{kg} / \mathrm{m}^{2}$ & $22.9 \pm 3.1$ & $23.2 \pm 2.6$ & $23.3 \pm 3.3$ & $22.3 \pm 3.1$ & 0.004 \\
\hline BMI groups, n (\%) & & & & & 0.006 \\
\hline$<20$ & $101(15.8)$ & $9(7.9)$ & $52(15.1)$ & $40(22.2)$ & \\
\hline $20-24.9$ & $379(59.4)$ & $78(68.4)$ & $193(56.1)$ & $108(60.0)$ & \\
\hline $25-29.9$ & $147(23.1)$ & $26(22.8)$ & $91(26.5)$ & $30(16.7)$ & \\
\hline $30-34.9$ & $11(1.7)$ & $1(0.9)$ & $8(2.3)$ & $2(1.1)$ & \\
\hline Polypharmacy, n (\%) & 367 (57.5) & $63(55.3)$ & $191(55.5)$ & $113(62.8)$ & 0.239 \\
\hline Multimorbidity, n (\%) & $591(92.6)$ & $105(92.1)$ & 317 (92.2) & $169(93.9)$ & 0.741 \\
\hline \multicolumn{6}{|l|}{ Medical disorders, n (\%) } \\
\hline Hypertension & $566(88.7)$ & $100(87.7)$ & $301(87.5)$ & $165(91.7)$ & 0.316 \\
\hline Coronary artery disease & $172(27.0)$ & $26(22.8)$ & $93(27.0)$ & $53(29.4)$ & 0.452 \\
\hline Heart failure & $8(1.3)$ & $1(0.9)$ & $2(0.6)$ & $5(2.8)$ & 0.092 \\
\hline Stroke & $21(3.3)$ & $5(4.4)$ & $6(1.7)$ & $10(5.6)$ & 0.052 \\
\hline \multicolumn{6}{|c|}{$\begin{array}{l}\text { Categorical variables are described as frequencies ( } \mathrm{n} \text { ) and percentages (\%). Continuous variables are } \\
\text { described using means and standard deviations. Comparisons were conducted using the chi-square } \\
\text { test or Fisher's exact test for categorical variables and one-way ANOVA for continuous variables. }\end{array}$} \\
\hline eGFR estimated glomer & rate, $B N$ & y mass $i$ & & & \\
\hline
\end{tabular}




\begin{tabular}{|c|c|c|c|c|c|}
\hline Characteristics & $\begin{array}{l}\text { All } \\
(n=638)\end{array}$ & $\begin{array}{l}\text { Nonfrail } \\
(n=114)\end{array}$ & $\begin{array}{l}\text { Prefrail } \\
(n=344)\end{array}$ & $\begin{array}{l}\text { Frail } \\
(n=180)\end{array}$ & $P$-value \\
\hline Osteoarthritis & $355(55.6)$ & $57(50.0)$ & $191(55.5)$ & $107(59.4)$ & 0.283 \\
\hline Chronic pulmonary diseases & $18(2.8)$ & $1(0.9)$ & $10(2.9)$ & $7(3.9)$ & 0.244 \\
\hline $\mathrm{eGFR}<60 \mathrm{~mL} / \mathrm{min} / 1.73 \mathrm{~m}^{2}$ & $224(35.1)$ & $38(33.3)$ & $110(32.0)$ & $76(42.2)$ & 0.062 \\
\hline \multicolumn{6}{|c|}{$\begin{array}{l}\text { Categorical variables are described as frequencies ( } \mathrm{n} \text { ) and percentages (\%). Continuous variables are } \\
\text { described using means and standard deviations. Comparisons were conducted using the chi-square } \\
\text { test or Fisher's exact test for categorical variables and one-way ANOVA for continuous variables. }\end{array}$} \\
\hline \multicolumn{6}{|c|}{ eGFR estimated glomerular filtration rate, $B M I$ body mass index } \\
\hline
\end{tabular}

\section{Differences in Fried frailty phenotype components between men and women}

In this study, frailty status varied according to sex. Frailty was more prevalent in women than in men (29.9\% and $26.8 \%$, respectively), but the difference was not statistically significant for the category of two states of the Fried frailty phenotype $(P=0.388)$ (Table 3$)$. Of the five Fried frailty phenotype components, the proportion of participants with low grip strength was the highest (68.0\%). This criterion was also the most prevalent among the men and women's groups. Compared with the men's group, the women's group experienced a lower grip strength $(75.4 \%$ vs. $62.1 \%, P=0.001)$ and low walking speed $(44.7 \%$ vs. $26.8 \%, P$ $<0.001)$, but less physical activity ( $31.3 \%$ vs. $43.8 \%, P=0.002)$. 
Table 3

Fried frailty phenotype and its components according to sex

\begin{tabular}{|c|c|c|c|c|}
\hline Characteristics & $\begin{array}{l}\text { All } \\
(n=638)\end{array}$ & $\begin{array}{l}\text { Men } \\
(n=354)\end{array}$ & $\begin{array}{l}\text { Women } \\
(n=284)\end{array}$ & $P$-value ${ }^{\mathrm{a}}$ \\
\hline \multicolumn{4}{|c|}{ Fried frailty phenotype (3 states), n (\%) } & 0.028 \\
\hline Non-frail & $114(17.9)$ & $76(21.5)$ & $38(13.4)$ & \\
\hline Pre-frail & $344(53.9)$ & $183(51.7)$ & $161(56.7)$ & \\
\hline Frail & $180(28.2)$ & $95(26.8)$ & $85(29.9)$ & \\
\hline \multicolumn{4}{|c|}{ Fried frailty phenotype (2 states), n (\%) } & 0.388 \\
\hline Non-frail ${ }^{b}$ & $458(71.8)$ & $259(73.2)$ & $199(70.1)$ & \\
\hline Frail & $180(28.2)$ & $95(26.8)$ & $85(29.9)$ & \\
\hline \multicolumn{5}{|c|}{ Components of Fried frailty phenotype, n (\%) } \\
\hline Weight loss & $117(18.3)$ & $64(18.1)$ & $53(18.7)$ & 0.931 \\
\hline Low grip strength & $434(68.0)$ & $220(62.1)$ & $214(75.4)$ & 0.001 \\
\hline Exhaustion & $142(22.3)$ & $70(19.8)$ & $72(25.4)$ & 0.112 \\
\hline Low walking speed & $222(34.8)$ & $95(26.8)$ & $127(44.7)$ & $<0.001$ \\
\hline Low physical activity & $244(38.2)$ & $155(43.8)$ & 89 (31.3) & 0.002 \\
\hline \multicolumn{5}{|c|}{$\begin{array}{l}\text { Categorical variables are described as frequencies }(\mathrm{n}) \text { and percentages }(\%) \text {. Comparisons were } \\
\text { conducted using the chi-square test. }\end{array}$} \\
\hline \multicolumn{5}{|c|}{ a'Men's group vs. women's group. } \\
\hline
\end{tabular}

\section{Associated factors of frailty in older outpatients with T2DM}

Univariate and multivariate logistic regression analyses were performed to identify the potential factors associated with frailty (Table 4). In the adjusted model, two factors that increased the odds of frailty were older age and $\mathrm{BMI}<20 \mathrm{mg} / \mathrm{m}^{2}$. In contrast, higher education and productive work were inversely associated with frailty. While all four factors were associated with frailty in women, only age and productive work were associated with frailty in men (Table 5). 
Table 4

Factors associated with frailty in the logistic regression analysis $(n=638)$

\begin{tabular}{|c|c|c|c|c|}
\hline \multirow[t]{3}{*}{ Variables } & \multicolumn{2}{|l|}{ Univariate } & \multicolumn{2}{|l|}{ Multivariate } \\
\hline & OR & P-value & Adjusted OR & P-value \\
\hline & (95\% Cl) & & $(95 \% \mathrm{Cl})$ & \\
\hline Age & $1.09(1.07-1.13)$ & $<0.001$ & $1.08(1.05-1.11)$ & $<0.001$ \\
\hline Women & $1.17(0.82-1.65)$ & 0.388 & & \\
\hline Living alone & $0.83(0.47-1.46)$ & 0.521 & & \\
\hline Productive work & $0.09(0.03-0.30)$ & $<0.001$ & $0.11(0.03-0.36)$ & $<0.001$ \\
\hline Higher education & $0.70(0.49-0.99)$ & 0.042 & $0.64(0.42-0.98)$ & 0.041 \\
\hline \multicolumn{5}{|l|}{ Marital status } \\
\hline Single & 1 (reference) & & & \\
\hline Married & $2.10(0.25-17.49)$ & 0.498 & & \\
\hline Divorced/Widowed & $3.43(0.40-29.21)$ & 0.260 & & \\
\hline \multicolumn{5}{|l|}{ BMI groups } \\
\hline $20-24.9$ & 1 (reference) & & 1 (reference) & \\
\hline$<20$ & $1.65(1.04-2.60)$ & 0.033 & $1.96(1.16-3.32)$ & 0.012 \\
\hline $25-29.9$ & $0.64(0.41-1.02)$ & 0.060 & $0.70(0.43-1.15)$ & 0.157 \\
\hline $30-34.9$ & $0.56(0.12-2.62)$ & 0.460 & $0.64(0.13-3.21)$ & 0.586 \\
\hline Polypharmacy & $1.36(0.95-1.93)$ & 0.093 & & \\
\hline Multimorbidity & $1.31(0.65-2.64)$ & 0.448 & & \\
\hline Hypertension & $1.56(0.86-2.84)$ & 0.142 & & \\
\hline Coronary artery disease & $1.19(0.81-1.74)$ & 0.375 & & \\
\hline Osteoarthritis & $1.24(0.88-1.76)$ & 0.226 & & \\
\hline $\mathrm{eGFR}<60 \mathrm{ml} / \mathrm{min} / 1.73 \mathrm{~m}^{2}$ & $1.53(1.07-2.18)$ & 0.019 & & \\
\hline \multicolumn{5}{|c|}{$\begin{array}{l}\text { Variables that had a } P \text {-value }<0.2 \text { in the univariate regression were included in the multiple regression. } \\
\text { Only variables that had a } P \text {-value }<0.05 \text { in the multiple regression are shown. }\end{array}$} \\
\hline eGFR estimated glomerular & on rate, $B M /$ body $r$ & dex, $C$ & dence interval, & ds ratio \\
\hline
\end{tabular}


Table 5

Factors associated with frailty in the logistic regression analysis according to sex

\begin{tabular}{|c|c|c|c|c|}
\hline \multirow[t]{3}{*}{ Variables } & \multicolumn{2}{|l|}{ Men $(n=354)$} & \multicolumn{2}{|l|}{ Women $(n=284)$} \\
\hline & Adjusted OR & P-value & Adjusted OR & P-value \\
\hline & $(95 \% \mathrm{Cl})$ & & $(95 \% \mathrm{Cl})$ & \\
\hline Age & $1.06(1.03-1.10)$ & 0.001 & $1.11(1.06-1.16)$ & $<0.001$ \\
\hline Productive work & $0.08(0.01-0.62)$ & 0.015 & $0.19(0.04-0.89)$ & 0.035 \\
\hline Higher education & & & $0.41(0.21-0.83)$ & 0.013 \\
\hline \multicolumn{5}{|l|}{ BMI groups } \\
\hline $20-24.9$ & & & 1 (reference) & \\
\hline$<20$ & & & $2.43(1.12-5.30)$ & 0.025 \\
\hline $25-29.9$ & & & $0.42(0.18-1.01)$ & 0.053 \\
\hline $30-34.9$ & & & $0.61(0.11-3.51)$ & 0.578 \\
\hline \multicolumn{5}{|c|}{$\begin{array}{l}\text { Variables that had a } P \text {-value }<0.2 \text { in the univariate regression were included in the multiple regressior } \\
\text { Only variables that had a P-value }<0.05 \text { in the multiple regression are shown. }\end{array}$} \\
\hline
\end{tabular}

\section{Discussion}

Frailty is an expression of physiological impairments and decreased functional reserve in multiple organ systems as a part of the ageing process, whereas T2DM is a pathological dysfunction characterised by hyperglycaemia and insulin resistance. These two clinical states can appear concurrently or consecutively in older adults ${ }^{2}$. They share several common pathophysiological mechanisms, such as metabolic impairment, increased oxidative stress, inflammatory dysregulation, and sarcopenia ${ }^{22}$. The presence of frailty in older patients with T2DM can increase the likelihood of adverse events and mortality 23,24 , whereas pathological metabolic changes in T2DM can increase the likelihood of frailty in older adults ${ }^{22}$. Nevertheless, sex differences in the patterns of frailty among older patients with T2DM are not fully understood. The results of this study provide three key observations. First, the prevalence of frailty in older outpatients with T2DM in Vietnam was $28.2 \%$. There was a higher prevalence of frailty in women than in men, but the difference was not statistically significant. Second, there were differences in some characteristics between the men's and women's groups. Third, older age, productive work, higher education, and $\mathrm{BMI}<20 \mathrm{~kg} / \mathrm{m}^{2}$ were associated with frailty in the total study population and women, but only the first two factors were associated with frailty in men.

In a recent meta-analysis, the median community frailty prevalence using the frailty phenotype in individuals with diabetes was $13 \%$, whereas the prevalence of frailty in outpatient populations varied 
widely due to heterogeneity in study settings, demographics, and especially in frailty assessment methods and differences in how frailty components were specified ${ }^{2}$. Our multicentre study is the first in Vietnam to find that the prevalence of frailty in older outpatients with T2DM was $28.2 \%$ when the Fried phenotype was used. Despite the differences in frailty assessment methods, our results are in accordance with the Action in Diabetes and Vascular Disease: Preterax and Diamicron Modified Release Controlled Evaluation (ADVANCE) trial using the frailty index and a recent study in Taiwan using the Tilburg frailty indicator showed that the prevalence of frailty in older outpatients with T2DM were $25.6 \%$ and $26.6 \%$, respectively ${ }^{25,26}$. Since the benefits from intensive glucose-lowering and glycaemic goals were altered in patients with frailty 9,25 , the high overlap between the two states found in the previous studies and ours highlights the importance of identifying frailty in older patients with diabetes.

The physiological variability in the ageing process between men and women and sex differences in biological factors (e.g. inflammatory cytokines, abdominal adiposity, and cognitive impairment) and psychosocial factors (e.g. healthcare utilisation and self-reported behaviours) may interactively contribute to sex differences in frailty ${ }^{27}$. Our study found that women were more likely to be frail than men in the diabetic population. This finding is consistent with a meta-analysis showing that older women have higher frailty index scores than older men ${ }^{11}$. However, the female sex as an associated factor of frailty was found in some studies, but no significant association was found in other studies ${ }^{28,29}$. Among older adults with T2DM, a recent study revealed a higher rate of frailty in women than in men, but sex was not a significant factor associated with frailty ${ }^{26}$. Based on the positive association between age and frailty ${ }^{28}$, the greater prevalence of frailty in our women's group may be related to a higher mean age in the women's group than in the men's group. Further research in a larger population and long-term follow-up is needed to elucidate the presence or absence of an association between the female sex and frailty.

Previous evidence from the Study of Osteoporotic Fractures showed that older women with diabetes had a greater decline in walking speed, but not in handgrip strength, than older women without diabetes ${ }^{30}$. This finding can be explained by the results from the Health, Aging, and Body Composition Study showing a decline in leg muscle strength and quality, but no differences in arm muscle strength and quality between older adults with and without T2DM ${ }^{31}$. However, interestingly, our study revealed that low grip strength was the most frequent component of the frailty phenotype in older adults with T2DM (68.0\%), but not low walking speed. Our contradictory findings can be explained by variations within the Fried frailty criteria used, especially in handgrip strength protocols. Although handgrip strength is a reliable assessment of muscle weakness, the values of this method could be influenced by many factors, such as different dynamometer, posture and arm position, dominant and non-dominant hands, and the differences in normative reference values stratified by the BMI cut-off points between world regions ${ }^{32,33}$. Our study used the original Fried frailty criteria with grip strength stratified by the BMI cut-off points for developed regions ${ }^{21}$, but not for developing regions such as Vietnam. This may explain the high rate of weakness assessed by grip strength in our study population. While Tamura et al. set the cut-off points for weakness as handgrip strength $<26 \mathrm{~kg}$ in men and $<18 \mathrm{~kg}$ in women regardless of the BMl, they found 
$49.5 \%$ of older outpatients with cardiometabolic disease having low grip strength. It was also the most frequent component of the Fried phenotype ${ }^{34}$.

Consistent with two previous studies including older adults with diabetes ${ }^{34,35}$, our study found significantly lower handgrip strength and slower walking speed in women than in men. These findings can be explained by several mechanisms. First, muscle mass and strength are determined by metabolic characteristics based on the regulation of sex hormones in nutrient sensing and the metabolism of organic compounds. In men, higher basal insulin levels promote more glycogen synthesis in muscle cells, and higher testosterone levels coupled with upregulated insulin-like growth factor signalling, results in greater muscle mass and strength ${ }^{36}$. A lower skeletal muscle mass than men, and oestrogen deficiency upon menopause negatively affects skeletal muscle protein turnover in women ${ }^{37,38}$. Second, in the older population, insulin resistance which can result in protein degradation, is associated with decreased quadriceps muscle strength and is a major risk factor for sarcopenia ${ }^{39,40}$. A recent study revealed that only older women with diabetes showed a higher prevalence of sarcopenia than those without diabetes, but these were not different in older men ${ }^{35}$. Third, women have a higher percentage of body fat than men, and there are sex differences in fat distribution. While men tend to have a central fat distribution with more abdominal visceral fat, women have a peripheral fat distribution with greater adipose tissue in the hips and thighs ${ }^{41}$. The data from the Framingham Heart Study revealed the impact of fat distribution on physical strength when intramuscular fat was associated with increased odds of low walking speed ${ }^{42}$. Taken together, the mechanisms may explain why men are faster and stronger than women, but other factors still contribute to the differences in physical performance between older men and women with T2DM.

Frailty is a geriatric syndrome that is affected simultaneously by many sociodemographic, physical, biological, and psychological factors. Identifying these factors may help geriatricians recognise those with a high likelihood of frailty. Importantly, understanding the disparities in the factors associated with frailty between men and women, may be necessary to develop an individualised approach for frailty prevention and management ${ }^{11}$. Our study found that age, $\mathrm{BMI}$, working status, and levels of education were factors associated with frailty. First, the findings are consistent with previous studies showing a positive association between frailty and increased chronological age in the overall older population, based on epidemiological evidence and biological mechanisms ${ }^{28,43}$. The putative mechanisms of increased susceptibility to frailty with ageing include loss of proteostasis, genomic instability, inflammation, epigenetic alterations, loss of stem cell regeneration, telomere shortening, deregulated nutrient sensing, and mitochondrial dysfunction ${ }^{44}$. Second, BMI is an important physical factor with a Ushaped association with frailty, in that $B M I \geq 25 \mathrm{~kg} / \mathrm{m}^{2}$ and $\mathrm{BMI}<20 \mathrm{~kg} / \mathrm{m}^{2}$ were associated with a higher prevalence of frailty in older adults ${ }^{45}$. However, little is known about the relationship between BMI and frailty in the older population with diabetes. Although excess body weight is a major risk factor for T2DM, there was a significantly decreased risk of mortality in overweight patients as compared with normal weight patients, and the survival benefits of obesity were only detected in older patients ${ }^{46}$. Our 
study found that only underweight, defined as $\mathrm{BMI}<20 \mathrm{~kg} / \mathrm{m}^{2}$, was associated with frailty in older patients with T2DM. Importantly, this association was only present in the women's group. This may be related to the fact that older men have a greater percentage of skeletal muscle mass than older women ${ }^{47}$, and $\mathrm{BMI}$ is inadequate to reflect older adults' strengths. Further studies are needed to understand the impact of BMI on frailty among older adults with T2DM.

The two protective factors of frailty found in our study were productive work and higher education. Previous studies have shown that older adults who continue to work or engage in any productive work beyond the retirement age are less likely to become frail. Prolonged work participation may offer a sense

of independence and social connections for older individuals ${ }^{48}$. However, until now, the impact of the type and density of work on frailty remains elusive. In addition to productive work, many studies have revealed that higher education levels can place older adults at a lower risk of being frail ${ }^{49,50}$. Although education is not directly related to the pathophysiology of frailty, a better education may impact an individual's lifestyle, such as increased awareness of healthy behaviours or increased ability to access social support and health services that may influence the progression of frailty ${ }^{50}$. Interestingly, higher education was a protective factor only in women, but not in men in the current study. This finding may require more insight into the sex-related preventive effects of higher education in the older population.

Our study has several limitations. First, the study was performed at only three geriatric clinics. Our results should be confirmed by larger multicentre studies. Second, the prevalence of medical disorders in our study may not be generalisable to the general older adult population since the sample only included patients visiting geriatric clinics. Third, the impact of comorbidities on frailty was not fully evaluated because of the low prevalence of some diseases, such as heart failure and stroke. Fourth, we were unable to evaluate the impact of specific antidiabetic agents and glycaemic goals on frailty because there were often switches of treatment regimens for diabetes and different individualised $\mathrm{HbA} 1 \mathrm{c}$ goals in every patient. Fifth, due to the cross-sectional nature of the study design, we could not evaluate causal relationships between frailty and the associated factors. Further longitudinal studies are warranted to clarify these relationships.

\section{Conclusions}

This is the first study to determine the prevalence of frailty in older patients with T2DM visiting geriatric clinics in Vietnam. Our findings add to the literature by demonstrating that older age and $\mathrm{BMI}<20 \mathrm{~kg} / \mathrm{m}^{2}$ were associated with increased odds of frailty, whereas higher education and productive work were associated with decreased odds of frailty. The sex differences in frailty in our geriatric outpatients with T2DM may suggest appropriate sex-related approaches to the management of frailty in these patients.

\section{Declarations}

Acknowledgements We thank the patients for their participation in our study. 
Author contributions H.T.N. conceived and designed the research. All authors were involved in data collection. H.T.N. and A.H.N. performed the statistical analysis. H.T.N. wrote the manuscript. All authors have read and approved the final manuscript.

Funding This study received no specific grant from any funding agency in the public, commercial, or notfor-profit sectors.

Data availability The datasets used and/or analysed during the current study are available from the corresponding author on reasonable request.

\section{Compliance with ethical standards}

Conflict of interest The authors declared no potential conflicts of interest with respect to the research, authorship, and/or publication of this article.

Ethical approval The present study was conducted in accordance with the guidelines of the Declaration of Helsinki and approved by the Ethics Committee of the University of Medicine and Pharmacy at Ho Chi Minh City, Vietnam (approval number, 01/QĐ-ĐHYD [approved on January 16, 2019]).

Informed consent Informed consent was obtained from all individual participants included in the study.

\section{References}

1. Hoogendijk, E. O. et al. Frailty: implications for clinical practice and public health. Lancet 394, 13651375, doi:10.1016/S0140-6736(19)31786-6 (2019).

2. Hanlon, P. et al. Frailty measurement, prevalence, incidence, and clinical implications in people with diabetes: a systematic review and study-level meta-analysis. Lancet Healthy Longev 1, e106-e116, doi:10.1016/S2666-7568(20)30014-3 (2020).

3. Damluji, A. A. et al. Frailty and cardiovascular outcomes in the National Health and Aging Trends Study. Eur Heart J 42, 3856-3865, doi:10.1093/eurheartj/ehab468 (2021).

4. Chen, C. L. et al. Frailty is Associated with an Increased Risk of Major Adverse Outcomes in Elderly Patients Following Surgical Treatment of Hip Fracture. Sci Rep 9, 19135, doi:10.1038/s41598-01955459-2 (2019).

5. Orkaby, A. R. Moving beyond chronological age: frailty as an important risk factor for cardiovascular disease. Eur Heart J 42, 3866-3868, doi:10.1093/eurheartj/ehab481 (2021).

6. Sinclair, A. et al. Diabetes and global ageing among 65-99-year-old adults: Findings from the International Diabetes Federation Diabetes Atlas, 9(th) edition. Diabetes Res Clin Pract 162, 108078, doi:10.1016/j.diabres.2020.108078 (2020).

7. Yang, Y. C. et al. Geriatric syndromes and quality of life in older adults with diabetes. Geriatr Gerontol Int 19, 518-524, doi:10.1111/ggi.13654 (2019). 
8. Veronese, N. et al. Frailty Is Associated with an Increased Risk of Incident Type 2 Diabetes in the Elderly. J Am Med Dir Assoc 17, 902-907, doi:10.1016/j.jamda.2016.04.021 (2016).

9. American Diabetes, A. 12. Older Adults: Standards of Medical Care in Diabetes-2021. Diabetes Care 44, S168-S179, doi:10.2337/dc21-S012 (2021).

10. Cosentino, F. et al. 2019 ESC Guidelines on diabetes, pre-diabetes, and cardiovascular diseases developed in collaboration with the EASD. Eur Heart J 41, 255-323, doi:10.1093/eurheartj/ehz486 (2020).

11. Gordon, E. H. et al. Sex differences in frailty: A systematic review and meta-analysis. Exp Geronto/89, 30-40, doi:10.1016/j.exger.2016.12.021 (2017).

12. Collard, R. M., Boter, H., Schoevers, R. A. \& Voshaar, R. C. O. Prevalence of frailty in communitydwelling older persons: a systematic review. J Am Geriatr Soc 60, 1487-1492, doi:10.1111/j.15325415.2012.04054.x (2012).

13. Shamliyan, T., Talley, K. M. C., Ramakrishnan, R. \& Kane, R. L. Association of frailty with survival: a systematic literature review. Ageing Res Rev 12, 719-736, doi:10.1016/j.arr.2012.03.001 (2013).

14. Oksuzyan, A., Juel, K., Vaupel, J. W. \& Christensen, K. Men: good health and high mortality. Sex differences in health and aging. Aging Clin Exp Res 20, 91-102, doi:10.1007/BF03324754 (2008).

15. Hubbard, R. E. \& Rockwood, K. Frailty in older women. Maturitas 69, 203-207, doi:10.1016/j.maturitas.2011.04.006 (2011).

16. WHO. World Report on Aging and Health. Available online: https://www.worldometers.info/worldpopulation/vietnam-population/. Accessed June 17, 2021). (2017).

17. Hinh, N. D. \& Minh, H. V. Public health in Vietnam: scientific evidence for policy changes and interventions. Glob Health Action 6, 20443, doi:10.3402/gha.v6i0.20443 (2013).

18. Ngoc, N. B., Lin, Z. L. \& Ahmed, W. Diabetes: What Challenges Lie Ahead for Vietnam? Ann Glob Health 86, 1, doi:10.5334/aogh.2526 (2020).

19. Nguyen, H. T., Nguyen, A. H. \& Nguyen, G. T. X. Prevalence and associated factors of frailty in patients attending rural and urban geriatric clinics. Australas J Ageing, doi:10.1111/ajag.13016 (2021).

20. Hubbard, R. E., Lang, I. A., Llewellyn, D. J. \& Rockwood, K. Frailty, body mass index, and abdominal obesity in older people. J Gerontol A Biol Sci Med Sci 65, 377-381, doi:10.1093/gerona/glp186 (2010).

21. Fried, L. P. et al. Frailty in older adults: evidence for a phenotype. J Gerontol A Biol Sci Med Sci 56, M146-156, doi:10.1093/gerona/56.3.m146 (2001).

22. Morley, J. E., Malmstrom, T. K., Rodriguez-Mañas, L. \& Sinclair, A. J. Frailty, sarcopenia and diabetes. J Am Med Dir Assoc 15, 853-859, doi:0.1016/j.jamda.2014.10.001 (2014).

23. Wong, E. et al. Diabetes and risk of physical disability in adults: a systematic review and metaanalysis. Lancet Diabetes Endocrinol 1, 106-114, doi:10.1016/S2213-8587(13)70046-9. (2013).

24. Cacciatore, F. et al. Clinical frailty and long-term mortality in elderly subjects with diabetes. Acta Diabeto/ 50, 251-260, doi:10.1007/s00592-012-0413-2 (2013). 
25. Nguyen, T. N. et al. The Impact of Frailty on the Effectiveness and Safety of Intensive Glucose Control and Blood Pressure-Lowering Therapy for People With Type 2 Diabetes: Results From the ADVANCE Trial. Diabetes Care 44, 1622-1629, doi:10.2337/dc20-2664 (2021).

26. Lin, C. L., Yu, N. C., Wu, H. C. \& Liu, Y. C. Risk factors associated with frailty in older adults with type 2 diabetes: A cross-sectional study. J Clin Nurs, doi:10.1111/jocn.15953 (2021).

27. Hagg, S. \& Jylhava, J. Sex differences in biological aging with a focus on human studies. Elife 10, doi:10.7554/eLife.63425 (2021).

28. Feng, Z. et al. Risk factors and protective factors associated with incident or increase of frailty among community-dwelling older adults: A systematic review of longitudinal studies. PLoS One 12, e0178383, doi:10.1371/journal.pone.0178383 (2017).

29. Llibre Rodriguez, J. J. et al. The Prevalence and Correlates of Frailty in Urban and Rural Populations in Latin America, China, and India: A 10/66 Population-Based Survey. J Am Med Dir Assoc 19, 287295 e284, doi:10.1016/j.jamda.2017.09.026 (2018).

30. Lee, C. G. et al. Changes in physical performance in older women according to presence and treatment of diabetes mellitus. J Am Geriatr Soc 61, 1872-1878, doi:10.1111/jgs.12502 (2013).

31. Park, S. W. et al. Accelerated loss of skeletal muscle strength in older adults with type 2 diabetes: the health, aging, and body composition study. Diabetes Care 30, 1507-1512, doi:10.2337/dc06-2537 (2007).

32. Sousa-Santos, A. R. \& Amaral, T. F. Differences in handgrip strength protocols to identify sarcopenia and frailty - a systematic review. BMC Geriatr 17, 238, doi:10.1186/s12877-017-0625-y (2017).

33. Dodds, R. M. et al. Global variation in grip strength: a systematic review and meta-analysis of normative data. Age Ageing 45, 209-216, doi:10.1093/ageing/afv192 (2016).

34. Tamura, Y. et al. Prevalence of frailty, cognitive impairment, and sarcopenia in outpatients with cardiometabolic disease in a frailty clinic. BMC Geriatr 18, 264, doi:10.1186/s12877-018-0955-4 (2018).

35. Kang, S. et al. Sex differences in sarcopenia and frailty among community-dwelling Korean older adults with diabetes: The Korean Frailty and Aging Cohort Study. J Diabetes Investig 12, 155-164, doi:10.1111/jdi.13348 (2021).

36. Comitato, R., Saba, A., Turrini, A., Arganini, C. \& Virgili, F. Sex hormones and macronutrient metabolism. Crit Rev Food Sci Nutr 55, 227-241, doi:10.1080/10408398.2011.651177 (2015).

37. Doherty, T. J. Invited review: Aging and sarcopenia. J Appl Physiol (1985) 95, 1717-1727, doi:10.1152/japplphysiol.00347.2003 (2003).

38. Collins, B. C., Laakkonen, E. K. \& Lowe, D. A. Aging of the musculoskeletal system: How the loss of estrogen impacts muscle strength. Bone 123, 137-144, doi:10.1016/j.bone.2019.03.033 (2019).

39. Barzilay, J. I. et al. Insulin resistance is associated with decreased quadriceps muscle strength in nondiabetic adults aged >or=70 years. Diabetes Care 32, 736-738, doi:10.2337/dc08-1781 (2009). 
40. Wang, X., Hu, Z., Hu, J., Du, J. \& Mitch, W. E. Insulin resistance accelerates muscle protein degradation: Activation of the ubiquitin-proteasome pathway by defects in muscle cell signaling. Endocrinology 147, 4160-4168, doi:10.1210/en.2006-0251 (2006).

41. Karastergiou, K., Smith, S. R., Greenberg, A. S. \& Fried, S. K. Sex differences in human adipose tissues - the biology of pear shape. Biol Sex Differ 3, 13, doi:10.1186/2042-6410-3-13 (2012).

42. Therkelsen, K. E., Pedley, A., Hoffmann, U., Fox, C. S. \& Murabito, J. M. Intramuscular fat and physical performance at the Framingham Heart Study. Age (Dordr) 38, 31, doi:10.1007/s11357-016-9893-2 (2016).

43. Ferrucci, L., Levine, M. E., Kuo, P. L. \& Simonsick, E. M. Time and the Metrics of Aging. Circ Res 123, 740-744, doi:10.1161/CIRCRESAHA.118.312816 (2018).

44. Lopez-Otin, C., Blasco, M. A., Partridge, L., Serrano, M. \& Kroemer, G. The hallmarks of aging. Cel/ 153, 1194-1217, doi:10.1016/j.cell.2013.05.039 (2013).

45. Rietman, M. L. et al. The Association between BMI and Different Frailty Domains: A U-Shaped Curve? J Nutr Health Aging 22, 8-15, doi:10.1007/s12603-016-0854-3 (2018).

46. Gao, F. et al. Impact of obesity on mortality in patients with diabetes: Meta-analysis of 20 studies including 250,016 patients. J Diabetes Investig 9, 44-54, doi:10.1111/jdi.12677 (2018).

47. Janssen, I., Heymsfield, S. B., Wang, Z. M. \& Ross, R. Skeletal muscle mass and distribution in 468 men and women aged 18-88 yr. J Appl Physiol (1985) 89, 81-88, doi:10.1152/jappl.2000.89.1.81 (2000).

48. Sewdas, R. et al. Why older workers work beyond the retirement age: a qualitative study. BMC Public Health 17, 672, doi:10.1186/s12889-017-4675-z (2017).

49. Hoogendijk, E. O. et al. Explaining the association between educational level and frailty in older adults: results from a 13-year longitudinal study in the Netherlands. Ann Epidemio/ 24, 538-544 e532, doi:10.1016/j.annepidem.2014.05.002 (2014).

50. Kendhapedi, K. K. \& Devasenapathy, N. Prevalence and factors associated with frailty among community-dwelling older people in rural Thanjavur district of South India: a cross-sectional study. BMJ Open 9, e032904, doi:10.1136/bmjopen-2019-032904 (2019). 